\title{
Water Resources Management in an Interdisciplinary and Changing Context
}

\author{
Rodrigo Maia $•$ Luis S. Pereira
}

Published online: 25 November 2014

(C) Springer Science+Business Media Dordrecht 2014

The great change and adaptation in water policy and management that occurred in the last decade in Europe and in the world resulted in water resources management being consistently in the international agenda. Having that in mind, the 8th International Conference of EWRA, held in Porto, Portugal, 26th-29th June 2013, and dedicated to "Water Resources Management in an Interdisciplinary and Changing Context" was a milestone for the assessment of the progress made in achieving sustainable management of aquatic systems and resources through an interdisciplinarity of knowledge and work, both at the European level and worldwide. The meeting was also the opportunity to pay tribute to two distinguished water researchers and scientists: Professor Evan Vlachos and Professor Luís Santos Pereira.

The Conference intended to be a platform of discussion and sharing of information and experiences between scientists and professionals from Europe and from other regions around the world, which are facing new challenges related to water resource management. It appeared clear that European Member States need to share know-how and enhance capacity building in order to foster the implementation of a common legislation at the European level, which can benefit from different approaches and experiences and be beneficial to other countries worldwide.

The Conference focused on broad issues and themes of great interest to water researchers and professionals, both in the European and the International communities and contexts: (i) the Water Framework Directive - implementation status and lessons learned, (ii) Water Resources Management, which dealt with innovative methodologies in water resources management and policies, and (iii) Water related specific topics, mostly focused on the ones at the cutting edge of future innovations in this scientific area. Following the Conference and the very fruitful and valuable discussion enabled by the attendance of scientists and researchers from different European and non-European countries, a strong interest in gathering some of the main findings and contributions shared emerged. This Special Issue was compiled for that purpose, trying to

\footnotetext{
R. Maia $(\bowtie)$

Division of Hydraulics, Water Resources and Environment; Civil Engineering Department; Faculty of Engineering, University of Porto, Rua Dr. Roberto Frias, s/n, 4200-465 Porto, Portugal

e-mail: rmaia@fe.up.pt

L. S. Pereira

CEER -Biosystems Engineering, Institute of Agronomy, University of Lisbon, Tapada da Ajuda, 1349-017 Lisbon, Portugal

e-mail: 1spereira@isa.ulisboa.pt
} 
present a representative range of the main topics discussed during the Conference through the presentation of some of the accepted contributions.

More specifically, the research studies presented in this Special Issue were organized under five main areas of research interest: water resources management frameworks, incorporating not only the institutional aspects but also multi-level approaches; climate and climate change effects and adaptation, emphasizing the increasing need of their consideration in water resources management, more specifically on the assessment of future scenarios; floods modelling and management, taking into account the policy issues involved but also the importance of a risk management oriented approach; droughts and water scarcity, from the importance of the definition and use of indices to the socioeconomic aspects that have to be taken in due account and, finally, modelling for specific water resources management purposes, which is probably the most transversal subject and has assumed during the last decades an increasing and undeniable role in many different water resources management related areas.

Following directly the broad subject of the Conference, the water resources management framework area relates to the general frame of planning, development and management of water resources systems, taking into account the multiplicity of uses and the interdisciplinarity of aspects involved, namely institutional, social and political. Beyond the most direct definition and interpretation of water resources management, the authors emphasized the growing and more complex level of analysis necessary to embrace the different aspects involved, namely the more current approach of integrated river basin management. In that context, Wurbs 2014 describes the importance of institutional dimensions of water availability modelling, those taken into account in a modelling system developed to support regional and statewide planning, administration of water allocation systems, and other water resources management endeavours, based on Texas and US reality. The multi-dimensional analysis challenges are also discussed in Mix et al. 2014, in the context of the presentation of a methodology and process to analyse complex social-ecological systems, illustrated by the Upper Rio GrandeSan Luis Valley case study. Pulwarty and Maia 2014, on the other hand, focus on transboundary river basins, analysing the adequacy of the application of water resources management principles and of corresponding often-recommended governance frameworks to sustainable management of water resources, namely taking into account climate change effects and extremes such as droughts, through the comparison of two different continent realities: Northern America and Europe, assessing climatic risks in two different river basins. Finally, Sahin et al. 2014 highlight the constant challenge faced by decision makers of water allocation and competiveness in water use, presenting a modelling framework used to explore the sensitivity of long-term planning of water resources, namely taking into account water security and water supply reliability, applied to South-East Queensland, Australia.

In the same line of thought, the Conference set the stage for some interesting discussions on the incorporation and importance of climate change effects in water resources management and, at a more specific level, in the implementation of the WFD implementation. Garrote et al. 2014 analysed the water resources management under climate change in southern European river basin districts, highlighting significant regional disparities in vulnerability to climate change in agriculture. In parallel, two other research studies, Fraedrich et al. 2014 and Vasiliades et al. 2014 focused on innovative issues relative to rainfall-runoff and extreme rainfall estimation and modelling, the first deriving and validating a stochastic-dynamic model of rainfall-runoff chain in a global climate model environment, analysing climate change in terms of runoff sensitivity/elasticity and attribution measures, the second assessing nonstationarity in annual maximum rainfall series using climate covariates. Wang et al. 2014 and Kim et al. 2014 more specifically approached the concept of climate change projections 
and scenarios applicable to topics as different as the design of river dikes, in the first case, and wastewater allocation in the second.

Natural hazards, namely floods, are also a major concern for water managers, and a constant topic in their agenda. The Conference was also a platform to highlight the role and relevance of the Floods Directive, published in 2007, which is a current concern of the European Union Member States that were required to draw up flood risk maps by 2013 and establish flood risk management plans by 2015. In accordance, one of the most important aspects associated with floods management is the assessment of floods and the elaboration of the corresponding maps: Papaioannou et al. 2014 present a multi-criteria analysis framework for potential flood prone areas mapping while Bellos and Tsakiris 2014 dedicate their research paper to a valuable comparison of various methods for building representation for 2D flow modelling in urban areas. Pinho et al. 2014 compare two hydrodynamic models for flooding simulations at the river basin scale, stressing the importance of flood hazard maps in the context of the application of the Floods Directive. Finally, two approaches to flood risk awareness are discussed: Schulte and Schumann 2014 present two examples of the statistical evaluation of the effect of a reservoir in a multi-tributary catchment and Ouyang et al. 2014 describe a specific model for flood limit water level of cascade reservoirs that intends to optimize not only the flood control risk but also the economic benefits of reservoir groups in flood season.

Water scarcity and droughts largely affect the southern Europe, from where originate all related papers of this issue. Tsakiris et al. 2014 discuss the evaluation of measures of a drought contingency plan establishing two sets of criteria, beneficial and constraining criteria. The compatibility among criteria is expressed by the use of suitable fuzzy implications and an application to the city of Heraklion (Crete) is presented. Spiliotis et al. 2014 propose the establishment of several categories characterizing water scarcity and adopt a fuzzy multicriteria filtering approach. An example relative to the Ebro river basin, Spain, is used. Sechi and Zucca 2014 approached the water resource allocation in water scarcity conditions in a complex supply system by using the Bankruptcy Games techniques and reported an application to the Tirso-Flumendosa-Campidano system in Sardinia, Italy. The use of drought indices, mainly the SPI, is the object of various but quite different papers. Bonaccorso et al. 2014 propose an analytical methodology to characterize probabilistically the relationship between meteorological drought severity and areal extent and validated it for Sicily, Italy, for 19212005. Raziei et al. 2014 identified regional drought modes in Portugal using Principal Component Analysis to the SPI computed on various time scales using three precipitation datasets. Results suggest that the three datasets well agree, thus favouring the stability of the identified sub-regions. Buttafuoco et al. 2014 analyse drought in southern Italy (Calabria) using SPI with different time scales which were mapped using a geostatistical approach. On a different approach to map drought severity, Maia et al. 2014 present a methodological approach for socio-economic evaluation of drought effects considering the supply and demand characteristics of a region and the hydrological interlinked effects of drought situation, with application to southeast Portugal. A very different approach for monitoring of extremes was used by Bordi et al. 2014 that discussed the use of half-hourly ground-based GPS measurements of precipitable water vapor to support monitoring of extreme weather conditions, such as floods and meteorological dry/wet spells, as well as for drought assessment and for estimating the water availability in a given area.

At a broader scale, modelling has been assuming an increasing and leading role in water resources management. From modelling river flow time series as described in Patel and Ramachandran 2014, for supporting policy makers decisions regarding water use strategies definition to the application of new software for the redesign of environmental monitoring 
networks under the responsibility of public environmental agencies, as presented in Barca et al. 2014, these new models have proved to be important and versatile tools. More specific and restricted applications are also of main importance in the assessment of localized problems, e.g. aquifer salinization, as described in Colombani et al. 2014 whose paper focused on the calibration and application of a two-dimensional model for the evaluation of adaptation strategies to deal with aquifer salinization. Also, beyond the well know hydrological models and the evaluation of scenarios, some other levels can also be embraced by modelling tools, as for example policy aspects. In that context, Prinsen et al. 2014 describe the importance of the Delta model for freshwater policy analysis in the Netherlands. The combination of several models in a customised approach also represent a valuable input in supporting regional planning and water resources management. Finally, the use of models can also be a great support to assessing specific and sensitive problems as natural hazards.

This Special Issue intends to be a starting point for further discussion and research in the different topics closely related with water resources management, having in mind the difficult challenges that have been arising in the last decade and that have been defying both researchers and decision makers. The interdisciplinary dimension that has been assuming an increasing role in water resources management is only one of the corner stones in this area, setting the stage for all the challenges ahead.

\section{In Memoriam of Alfonso Sutera}

On December 8, 2013, Alfonso Sutera, Professor of Physics at Sapienza University, Roma, died suddenly and unexpectedly at his home in Rome. His passing marks the loss of one of the leading investigator in the field of Atmospheric Physics, a great "magister" and, not lastly, a great human being. He grew up culturally within the School of Meteorology in United States, where he went at the end of the seventies and worked until 1990 at the Yale University. He was the pioneer of the mechanism of stochastic resonance, first introduced in the early eighties to explain the almost regular transitions between ice ages and temperate climates. Also, he became known for his studies on the planetary-wave amplitude bimodality that characterizes the atmospheric regimes during winter months. His wide-ranging scientific interests led him to study with great enthusiasm also several aspects related to Hydrology and Remote Sensing. To mention are his efforts on drought monitoring and forecasting, the analysis of drought variability at large and regional scale, extreme events, and the use of GPS (both in Radio Occultation and ground-based) for sounding the atmosphere. His last research interests were directed mainly to the study of the potentials of ground-based GPS for hydrological applications and the stochastic resonance in a two-dimensional system.

He was an active Member of European Water Resources Association (EWRA) and American Meteorological Society (AMS). Just 1 month before his death (on October 8, 2013) he was elected member of the Accademia Nazionale dei Lincei, unfortunately too late to contribute to the scientific activities of the Academy. He contributed to two papers in this Journal issue.

Those who closely knew him know that he always worked with total dedication, intellectual honesty and great curiosity, becoming a reference for his students and collaborators. He strongly believed in family and friendship as immortal values; he showed high sensitivity to the problems of young students and suffering people, being always available for some help. His intellectual contribution and human qualities will be greatly missed. 
During the last EWRA meeting in Porto he confided to some Greek colleagues the desire to spend his old age in a Greek island with mild climate. We wish to think that he is there learning Greek, the language that fascinated him so much and that he began to study.

Acknowledgments The Editorial and Publishing Team is very thankful for the opportunity given in hosting this Special Issue.

\section{References}

\section{Water Resources Management Frameworks}

Wurbs, R., 2014. Institutional and hydrologic water availability in Texas

Mix, K., Lopes, V., Rast, W., 2014. A systems approach to understanding the evolution of the agro-socialecological system of the Upper Rio Grande-San Luis Valley, Colorado

Sahin, O., Stewart, R. A., Helfer, F., 2014. Bridging the water supply-demand gap in Australia: coupling water demand efficiency with rain-independent desalination supply

Pulwarty, R., Maia, R., 2014. Adaptation challenges in complex rivers around the world: the Guadiana and the Colorado basins

Kim, Y., Chung, E. S., Jun, S., 2014. Iterative framework for robust reclaimed wastewater allocation in a changing environment using multi-criteria decision making

\section{Climate and Climate Change Effects}

Fraedrich, K., Sielmann, F., Cai, D., Zhang, L., 2014. Validation of an ideal rainfall-runoff chain in a GCM environment

Garrote, L., Iglesias, A., Granados, A., Mediero, L., Martin-Carrasco, F., 2014. Quantitative assessment of climate change vulnerability of irrigation demands in Mediterranean Europe

Vasiliades, L., Galiatsatou, P., Loukas, A., 2014. Nonstationary frequency analysis of annual maximum rainfall using climate covariates

Wang, L., Van Gelder, P. H. A. J. M., Vrijling, J. K., Maskey, S., Ranasinghe, R., 2014. Risk-averse economic optimization in the adaptation of river dikes to climate change.

\section{Floods Modelling and Management}

Bellos, V., Tsakiris, G., 2014. Comparing various methods of building representation for 2D flood modelling in built up areas

Papaioannou, G., Vasiliades, L., Loukas, A., 2014. Multi-criteria analysis framework for potential flood prone areas mapping

Schulte, M., Schumann, A. 2014. Downstream-directed performance assessment of reservoirs in multi-tributary catchments by application of multivariate statistics

Pinho, J., Ferreira, R., Vieira, L., Schwanenberg, D., 2014. Comparison between two hydrodynamic models for flooding simulations at river Lima basin

Ouyang, S., Zhou, J., Li, C., Liao, X., Wang, H., 2014. Optimal design for flood limit water level of cascade reservoirs

\section{Drought and Water Scarcity}

Bonaccorso, B., Peres, D. J., Castano, A., Cancelliere, A. M., 2014. SPI-based probabilistic analysis of drought areal extent in Sicily

Bordi, I., Raziei, T., Pereira, L. S., Sutera, A., 2014. Ground-based GPS measurements of precipitable water vapor and their usefulness for hydrological applications

Raziei, T., Martins, D. S., Bordi, I., Santos, J. F., Portela, M. M., Pereira, L. S, Sutera, A., 2014. SPI modes of drought spatial and temporal variability in Portugal: comparing observations, PT02 and GPCC gridded datasets 
Tsakiris, G., Spiliotis, M. G., Vangelis, H., Tsakiris, P., 2014. Evaluation of measures for combating water shortage based on beneficial and constraining criteria

Spiliotis, M. G., Martin-Carrasco, F., Garrote, L., 2014. A fuzzy multi criteria categorization of water scarcity in complex water resources systems

Sechi, G. M., Zucca, R., 2014. Water resource allocation in critical scarcity conditions: a bankruptcy game approach

Buttafuoco, G., Caloiero, T., Coscarelli, R., 2014. Analyses of drought events in Calabria (Southern Italy) using Standardized Precipitation Index

Maia, R., Vivas, E., Serralheiro, R., Carvalho, M., 2014. Socioeconomic evaluation of drought effects. Main principles and application to Guadiana and Algarve case studies

\section{Modelling for Specific Water Resources Management Purposes}

Patel, S. S., Ramachandran, P., 2014. A comparison of machine learning techniques for modeling river flow time series: the case of upper Cauvery river basin

Colombani, N., Mastrocicco, M., Giambastiani, B. M. S., 2014. Predicting salinization trends in a lowland coastal aquifer: Comacchio (Italy)

Barca, E., Vurro, M., Morea, A., Passarella, G., 2014. MSANOS: Data-driven, multi-approach software for optimal redesign of environmental monitoring networks

Prinsen, G., Weiland, F. S., Ruijgh, E., 2014. The Delta model for fresh water policy analysis in the Netherlands 